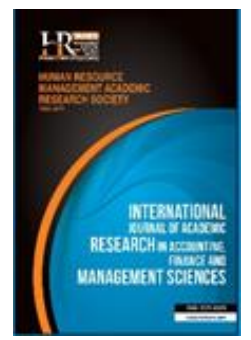

International Journal of Academic Research in Accounting, Finance and Management Sciences

Vol. 8, No.2, April 2018, pp. 37-47

E-ISSN: 2225-8329, P-ISSN: 2308-0337

(c) 2018 HRMARS

www.hrmars.com

To cite this article: Anghelache, C., Marinescu, A.I., Samson, T. (2018). Theoretical Characteristics of the Purchasing Power Parity in the EU Context, International Journal of Academic Research in Accounting, Finance and Management Sciences 8 (2): 37-47.

\title{
Theoretical Characteristics of the Purchasing Power Parity in the EU
} Context

\author{
Constantin ANGHELACHE ${ }^{1}$, Andreea - loana MARINESCU ${ }^{2}$, Tudor SAMSON ${ }^{3}$ \\ ${ }^{1}$ Bucharest University of Economic Studies/„Artifex” University of Bucharest, Romania, ${ }^{1}$ E-mail: actincon@yahoo.com \\ ${ }^{2,3}$ Bucharest University of Economic Studies, Romania, \\ 2E-mail: marinescu.andreea.ioana@gmail.com, ${ }^{3}$ E-mail: tudorsamson@gmail.com
}

\begin{abstract}
This article focuses on highlighting the main significant elements of international comparability. Until now, gross domestic product and, in particular, gross domestic product per capita are benchmarks to be used in international comparisons. However, even if we are deflating the macroeconomic indicators of results, in total and in terms of the assessment of the living standards of the population in a group of countries, it is somewhat distorted by other macroeconomic indicators that differ from one country to another. Thus, the issue of the consumer price index or the harmonized price index gives a whole new perspective on the living standards of the population in a country. From this point of view, the most relevant indicator that accurately expresses this level (standard) of living in a country compared to another country is the parity of purchasing power. The introduction of the euro in the European Union involves going through some interesting stages and that is why we must point out that not all the Member States of the European Union are also members of the monetary union. Thus, it is a question of comparing the countries within the European Union, but also of expanding the comparison outside the monetary union or other countries. The purchasing power parity idea is sometimes reduced to the standard purchasing power parity (SPC) that is specific to the achievement of international comparability of the gross domestic product, both on its totality and on its main structures. Purchasing power parity calculations are performed in several steps such as the initial parity referring to a single country, then the value of the standard parities by recalculation as a geometric mean, then the recalculation based on the standard parities where factor conversion and last but not least, to divide the values obtained at the time expressed in the national value of a country. This is why this is an interesting process that the authors have been preoccupied with to decipher and present it with precision in this study. Furthermore, the authors discuss the issue of the dynamics of macroeconomic indicators by structural elements, both in terms of comparable prices and of establishing the idea of ensuring comparability on total and structure. Reference is also made to measuring the inflation that is needed to bring the indicators to comparability.
\end{abstract}

Key words

Parity, International Comparison, Gross Domestic Product, Price Index, Euro Union

Received: 25 Apr $2018 \quad$ (c) The Authors 2018

Revised: 30 Apr $2018 \quad$ Published by Human Resource Management Academic Research Society (www.hrmars.com)

Accepted: 05 May 2018 This article is published under the Creative Commons Attribution (CC BY 4.0) license. Anyone may reproduce, distribute, translate and create derivative works of this article (for both commercial and noncommercial purposes), subject to full attribution to the original publication and authors. The full terms of this license may be seen at: http://creativecommons.org/licences/by/4.0/legalcode

\section{Introduction}

In this study, the authors started from the need to ensure the international comparability of the macroeconomic indicators of output, gross domestic product. They focused on the possibilities of other indicators such as deflated Gross Domestic Product, Gross Domestic Product per capita, and they further suggested the prospect of achieving international comparability and living standards, where the conclusion is it is only the purchasing power parity index that is able to ensure a proper hierarchy of countries in terms of their resources and the possibilities to ensure a certain comprehensibility of the living standards of one 
country or another. Successively, the authors analyze the standard purchasing power parity, which they present as a specific notion to the international comparison of macroeconomic indicators and first of all gross domestic product. It then deals with the analysis of the dynamics of the macroeconomic results indicators, with an emphasis on gross domestic product, gross domestic product or national income. It is expressed that the indicators are usually calculated and expressed in the current prices of the calculation period, ie the indices in nominal expression. We need to bring these indicators at comparable prices that give them real expression, comparability capacity. Referrals and analyzes are made in relation to component comparability, final use of gross domestic product, or structure of resources from which gross domestic product has been formed. The article focuses on the expression of comparable gross domestic product prices, taking into account that only a precise measurement of the inflation rate applied in the deflation process can provide macroeconomic indicators with relevance to ensure comparability. At this point, the study highlights the need to evaluate products and services, firstly evaluating constant prices that bring the indicators at the same level of volume and prices that will analyze the flows and stocks the real terms of the results obtained in a period of time or another. The measurement of prices and volumes is analyzed in the specific way that this theoretical aspect raises, which has a precise reflection in the analysis of comparability. The authors focus on presenting the advantages of the method of accounts in the matter of evaluation, which must be conceptually, statistically, methodologically understood, and then the applicability that is achieved in bringing data to a comparative level. Price and volume indices are specifically applied in the national accounts system, and here reference is made to the overall system of price and volume indices, price and volume indices for other aggregates of the national accounts system, and ultimately focus on the general principles of measurement of price and volume indices. In the final part of the article, the authors also refer to the issue of quality differences and price differences that need to be viewed in this context in order to provide real content of the calculated indicators. In the free market we have the prices the market gives, but a number of services are non-marketable and therefore there must be a possibility based on the principles that apply to services that are done outside the free market. Possible difficulties that may arise in applying the general principles are briefly presented to reveal what are the ways to measure real income in the economy. This is the way to significant elements that need to be considered. Also in the final part we refer to the choice of weights we use to establish the indices and to establish the base year, so that the elements of the international comparison of the price and volume indices are consistent and ensure such comparability that not to include errors in computation, expression and use.

\section{Literature review}

Angelini et al. (2014) have shown that the availability of capital requirements as a political instrument generates significant gains in macroeconomic stabilization. Anghel et al. (2017) studied the key aspects of calculating the price index and its use in deflating macroeconomic outcomes indicators. Anghelache et al. (2017) addressed a number of issues related to optimal government policies, given the implications for monetary policy and fiscal policy. Anghelache et al. (2013) studied the indicators used in macroeconomic analyzes. Azzimonti et al. (2016) studied the costs and benefits of balanced budget rules. Barro and Redlick (2011) have shown that tax changes affect GDP mainly through substitution effects rather than through wealth effects. Bassetto and Messer (2013) studied the role of the central bank's balance sheet in a monetary model and examined what changes would allow the central bank to pay interest on its debts. Censolo and Colombo (2008) analyzed the role of the composition of public consumption in a growth model of research and development in three sectors. Christiano et al. (2011) argued that the multiplier of government spending may be much higher than one when the lower limit on the nominal interest rate is linked. Farhi and Werning (2016) identified an aggregate demand outsourcing that can be corrected through macro-prudential interventions in financial markets. Kaplan and Violante (2014) developed a pattern of consumption response to tax incentive payments. Gali et al. (2007) studied how consumption increases in response to an increase in government spending. Greenwood and Nagel (2009) examined the hypothesis that inexperienced investors play a role in the formation of asset price bubbles. Mian et al. (2013) studied the correlation in households' balance sheet, consumption and the economic crisis. Romer and Romer (2010) investigated the macroeconomic effects of tax changes. Solomon 
et al. (2006) analyzed a number of aspects of European consumer behavior. Tracy and Wright (2016) studied the impact of refinancing on anticipated credit losses.

\section{Research methodology and data. Results and discussions}

Analysis of a country's development stage can be achieved statically from time to time on the basis of a comparison of the macroeconomic output indicators. When it comes to international comparison, the indicators used should be deflated and then brought to a similar level. For this purpose, for example, deflated per capita Gross Domestic Product may be used, expressed in the same currency. However, this indicator (GDP per capita in euro) is not entirely enlightening because it does not take into account domestic market prices to highlight the country's standard of living. Under these conditions, the most complex indicator (statistical variable) is the purchasing power parity index of population incomes. This solution is also demanded by Romania's belonging to the European Union, and the Member States can be correctly ranked at least in the life standard of the population.

The introduction of the single currency involves the determination of economic aggregates in the euro, in which comparison programs will continue because: not all EU Member States are also members of the Monetary Union; comparisons are also needed between EU and non-EU countries; the use of the euro does not automatically mean the elimination of existing price differences between Member States.

Comparing an EU country with a country outside the group can be used to standardize purchasing power. The standard purchasing power parity (PSP) is a specific notion of international comparison of Gross Domestic Product. Cash is defined in such a way that for each aggregate of expenditure the total EU obtained from the conversion of the values expressed in national currency by parities is equal to the total EU for that aggregate expressed in euro.

As a rule, a country's national currency is chosen as cash for expressing actual spending and purchasing power parities. Cash can also be the average for a certain group of countries, often in the European Union until the introduction of the euro.

Practical calculation is done through several steps: the parities are initially calculated, referring to a base country; parity values are standardized by recalculating as the simple geometric mean of parities for EU Member States; is calculated $\sum P I B_{P P C}^{U E}$ (where PIB $P P C$ is real gross domestic product recalculated on the basis of standard parities and $\sum P I B_{E C U}^{U E}$; conversion factor is determined as ratio, $\sum P I B_{P P C}^{U E}$ : $\sum P I B_{E C U}^{U E}$, being used in establishing GDP values transformed using standard parities in comparable values, dividing the values obtained under point (4) to GDP expressed in national currency, the standard purchasing power parities (PSP) are obtained.

The analysis of the evolution and trend of the economy is mainly expressed on the basis of the resulting macroeconomic indicators (Gross Domestic Product - PIB, Gross National Product, PNB, National Income - VN, etc.). to be expressed in comparable prices.

For the calculation of comparable price indicators (real expression), it is necessary to eliminate the influence of the price change from the magnitude of the value indices expressed in current prices (nominal indicators). For this purpose, price indices $\left(I_{p}\right)$ are calculated, which express the change in the prices of the goods that make up the aggregate considered. The price index is further used to calculate the value indicator in comparable prices by reporting the current price indicator to the price index.

Recalculation in comparable expression can be performed globally or analytically. For the Gross Domestic Product indicator, real-time recalculation is performed as follows:

- globally, by correcting with the global price index or GDP deflator, according to the relationship:

$$
P I B^{\text {comp }}=\frac{P I B^{c r t}}{D} \text {, }
$$

Where:

$\mathrm{PIB}^{\text {comp }}=$ gross domestic product in comparable prices;

$\mathrm{PIB}^{\mathrm{crt}}=$ gross domestic product in current prices;

$\mathrm{D}=$ deflator used. 
- by component, by reporting each element of Gross Domestic Product in current prices at price indices corresponding to the sphere of coverage of each component. The calculations are performed on the domains (branches) according to the aggregation used, according to the relation:

$$
P I B^{\text {comp }}=\frac{V A B_{\text {ind }}^{\text {crt }}}{I_{P}^{\text {ind }}}+\frac{V A B_{a g r}^{c r t}}{I_{P}^{a g r}}+\cdots+\frac{V A B_{a r}^{c r t}}{I_{P}^{a r}},
$$

Where:

$V A B_{\text {ind,agr,...ar }}^{\text {crt }}=$ Gross value added from industry, agriculture, ..., other branches in current prices;

$I P^{i n d, a g r, \ldots a r}=$ price indices of products and services created in each branch;

- on structural elements (gross and intermediate consumption), using the calculation relation:

$$
P I B^{c o m p}=\frac{P B^{c r t}}{I_{P}^{P C}}-\frac{C I^{c r t}}{I_{P}^{C I}},
$$

Where:

$\mathrm{PB}^{\mathrm{crt}}=$ the value of gross production in current prices;

$\mathrm{Cl}^{\mathrm{crt}}=$ value of intermediate consumption in current prices;

$I_{P}^{P i C i}=$ the price index for products and services included in gross output, i.e. intermediate consumption.

- on final use destinations of the Gross Domestic Product, considering the structure of GDP, after uses, based on the calculation formula:

$$
P I B^{C O M P}=\frac{C P_{p v}^{c r t}}{I_{P}^{C P}}+\frac{C P^{c r t}}{I_{P}^{C P L}}+\frac{F B C^{c r t}}{I_{P}^{F B C}}+\frac{E X N^{c r t}}{I_{P}^{E X N}},
$$

Where:

$$
C P_{p v}^{c r t}=\text { private consumption in current prices; }
$$

$C P_{p b}^{c r t}=$ public consumption in current prices;

$F B C^{c r t}=$ gross capital formation in current prices;

$E X N^{c r t}=$ net export in current prices;

$I_{P}^{C P, C P L, F B C, E X N}=$ the price index corresponding to the goods that make up each component of the final use of the gross domestic product.

After calculating the gross domestic product in comparable prices by one of the presented methods, the evolution of the respective aggregate is calculated by calculating the Gross Domestic Product Index (IPIB), following the relation:

$$
I P I B=\frac{P I B_{1}^{\text {comp }}}{P I B_{0}^{\text {comp }}} \text {. }
$$

It can be seen that this is an "index of the physical volume of gross domestic product", not influenced by price changes. Therefore, it expresses the real evolution of gross domestic product.

Economic growth studies based on GDP aggregates should be accompanied by an analysis of global per capita indicators. They have a special significance because they express the average size per person and the evolution of this indicator, over time or the ratio from country to country. The calculation relation is as follows:

$$
P I B L=\frac{P I B}{P},
$$


Respectively the dynamics of this indicator:

$$
I P I B L=\frac{P I B B_{1}^{c o m p}}{P_{1}}: \frac{P I B_{0}^{c o m p}}{P_{0}}=\frac{I P I B}{I P},
$$

Where:

$\mathrm{PIBL}=$ gross domestic product per capita;

$\mathrm{P}=$ average population (as a rule, population as of 1 July of the calculation year as a mean substitute);

IPIBL = Gross Domestic Product Indice per capita;

$\mathrm{IP}=$ average population index.

Gross domestic product per capita expresses the level of economic development more realistically. GDP per capita growth is significant as it correlates with GDP dynamics with population dynamics. For economic development and livelihoods, GDP growth (measured by the IPIB real index) needs to outstrip the population (IP), namely:

$I P I B>I P$.

- expressing comparable prices for measuring inflation

Except for some variables related to population, labor, production in natural expression, all flows and stocks presented in the system of accounts are expressed in monetary terms.

As a rule, the valuation method, which takes into account the market price for goods, services or similar assets, is preferred. Where information is not available, for example in the case of government nongovernment services, the valuation is based on production costs. If the two methods cannot be used, the recording of flows and stocks is made at the present value of future earnings.

Some costs, such as shipping costs, trade add-ons, and taxes, minus subsidies per product, determine the manufacturer and user of a given product to have a different perception of its value. To approximate the views of economic agents, all uses are recorded at the purchase price, taking into account the above elements, recording production at the basic price.

Imports and exports of products are counted at the border. All imports and exports are valued free on board (FOB), which means the customs value at the exporter's frontier. Transport and insurance services provided by foreign enterprises between the exporter's border and that of the importer are not included in the value of the good but are recorded as services. Since it is not possible to obtain the FOB value for all product subdivisions, the detailed foreign trade tables first show the import frontier values (CIFs). The transport and insurance services to the importer's customs frontier are included in the value of the imported goods. To the extent that these services are provided by national enterprises, a global adjustment is made on the basis of a coefficient equal to the FOB/CIF ratio in the accounts.

Expression in constant prices consists in determining the flows and stocks of a period the prices of the prior period, the purpose being to break down the variations in the value of flows and stocks into "price variations" and "volume variations" over time. The expression "in volume" is synonymous with "in constant prices".

Many flows and stocks, such as income, taxes, government transfers etc., do not have their own size in terms of price and quantity. The purchasing power of these variables can be obtained by deflating current values with an average price index, such as the end-use price index, excluding stock changes. Flows and stocks thus deflated are expressed "in real terms".

Economic analysis is about making comparisons in space, so between different national economies. The differences in values observed between the economic aggregates of a group of countries must thus be broken down to allow for the separation of volume and price differences.

In the short term, under moderate inflation conditions, observing price variations is of less interest than measuring supply and demand. In the long run, economic development studies cannot disregard the evolution of prices for the categories of goods and services. ${ }^{1}$

\footnotetext{
${ }^{1}$ The main objective is not simply to provide full measurement of the price and volume variation for the main aggregates, but at
} 
Comparing over time requires that the volume and prices of economic aggregates be measured as accurately as possible. The difference between the Laspeyres and Paasche weights is often important when it comes to this type of comparison, in which case the Fischer formula is recommended.

Economic accounts have the advantage of providing a framework to build a system of volume and price indices and to ensure the coherence of statistical data. The advantages of the method of accounting in the evaluation issue can be summarized as follows:

- in the conceptual field, the use of a framework covering the entire economic system requires a coherent specification of prices and volume for different products and flows of the economic system;

- on a statistical basis, the use of economic accounts imposes restrictions that need to be met, both in current and constant prices, being necessary to ensure price and volume consistency;

- in the methodological plan, it is necessary to develop an integrated system of price and volume indices within the system of economic accounts, which will give the analyst additional control possibility. Assuming the establishment of a balanced set of tables of resources and uses in current prices, building such tables at constant prices allows the automatic deduction of a system of default price indices;

- in the field of measuring economic outcomes, the National Accounts System method allows to determine the evolution of prices and volume for certain accounting balances, these being based on other items of the accounts.

- The main scope of price and volume indices in the System of National Accounts

Within the flows that appear in the economic accounts in current prices, there are some related to products for which the distinction between price variations and volume changes is the same as that made at microeconomic level. For other streams, this distinction is much more difficult to do.

In the first case, we are in the presence of a flow that covers a set of elementary operations with goods and services, the value of each being equal to the product of a given number of physical units and their unit price. It is sufficient, in this case, to know the decomposition of the flow in the item operations to determine the average variation in price and volume.

In the second case, which refers both to a number of financial distribution operations and financial intermediation and to certain balances such as value added, it is more difficult, even impossible; to decompose directly the current values into the price and volume components. In this case, specific solutions must be adopted.

There is a need to measure the real purchasing power of a certain number of aggregates, such as employee remuneration, household disposable income or national income. This can be done by deflating these aggregates through a price index of the goods and services that can be purchased from that market.

We specify that the objective and method of calculating the actual purchasing power differ from those used in the case of the deflation of the value of goods and services, as well as the balances of the accounts. For the latter, an integrated system of price and volume indices can be established, which will be useful in measuring economic growth and comparative analysis.

- The overall system of price indices and physical volume

The systematic breakdown of the change in values in its components: 'price variation' and 'volume change' is limited to flows representing operations recorded in goods and services accounts (0) and production accounts (I). The breakdown is done for branch and national economy data. Flows representing the balances of different accounts, such as value added, cannot be directly converted into price and volume components, this can only be done indirectly, starting from the flows of the corresponding transaction.

The use of the accounts framework requires a two-fold restriction on the data process, as follows: The balance of the goods and services account must be achieved in both constant and current prices for each consecutive two consecutive years; each flow in the total economy must be equal to the sum of the corresponding flows for the different branches; it is necessary that all the value change of the operations be attributed either to a price variation or to a variation in volume or the combination of the two. 
Responding to this triple requirement, valuation of goods and service accounts and production accounts in constant prices allows for an integrated set of price and volume indices. The dimensions considered for building such an integrated assembly are as follows:

- Price and volume indices for other aggregates of SCNs

It is necessary, in the various analyzes, that other aggregates be separated into their own price and volume components: stocks at the beginning and end of the period; stocks of fixed assets produced; the remuneration of employees must be expressed in constant prices;

- General principles for measuring price and volume indices

The compilation of an integrated system of price and volume indices is based on the assumption that for a given homogeneous good or service, its value $(v)$ is equal to the unit price $(p)$ multiplied by the number of units (q), respectively:

$$
v=p \times q .
$$

The price is defined as the value of a unit of product whose quantities are homogeneous, not only in the physical sense, but also of a certain number of qualitative characteristics. For each aggregate of goods and services transactions presented in the accounts, the values of the price and quantity must be established in such a way that:

$=\left[\begin{array}{c}\text { value } \\ \text { index }\end{array}\right]\left[\begin{array}{c}\text { price } \\ \text { index }\end{array}\right]\left[\begin{array}{c}\text { volume } \\ \text { index }\end{array}\right]$

This means that each variation in the value of a given stream must be attributed either to a price variation, volume variation, or a combination of two.

In the case of goods operations, it is impractical to define the physical unit and, consequently, the unit price.

In the case of service operations, it is more difficult to distinguish the characteristics that determine physical unity, and so there may be difficulty with the criteria that can be applied.

This occurs in the case of financial intermediation services, wholesale and retail services, business services, education, research and development, health, defense, public order.

Given the importance of services, it is essential to find common solutions, even if they are conventional, in choosing physical units.

- The issue of differences in quality and price differences

Alongside the physical characteristics that are taken into account for product identification, product quality plays an important role and, at the same time, raises some statistical problems.

For some goods and services intended for a particular consumption there are several variants of different qualities and obviously characterized by different unit prices.

Differences in quality are reflected by various characteristics: physical; psycho-sensorial; reliability; places of delivery; delivery times; sales conditions.

In the case of given physical characteristics, differences affecting other factors make physical units not the same in economic sense, and their value changes from one unit to another. These differences in unit value are considered as volume differences, and not as price differences.

In fact, the payment made when buying a good that does not only cover the price of the good but also the services associated with the supply of that product. This situation is reflected in the accounts, through the table of resources and uses at basic prices, where the value of the commercial additions and the transport tax are recorded separately.

Within a market and for the same period, the coexistence of several unit values can be considered as an index of qualitative differences. Thus, models of the same range of vehicles have to be treated as 
different products, as a distinction has to be made between rail journeys if they are carried out in Class I or II.

Establishing price and volume measurements impose a product nomenclature to the fullest possible level so that each product identified in this way displays a maximum of homogeneity, whatever the level of disaggregation used in presenting the results.

The qualitative dimension must be taken into account when subject to variations in time and variations in quality due to changes in the physical characteristics of the product. It should be considered as a variation in volume, not as a price variation. Similarly, the effects of aggregation must be taken into account. In situations such as lack of information or price differentiation, both reflecting a limited choice of freedom or the existence of a parallel market, it is necessary to consider that the differences in unit value are not differences in quality but price differences.

There are price differences when vendors find themselves in a situation that allows them to charge different prices to different categories of buyers, and for similar goods and services, sold under the same conditions. $^{2}$

\section{- Principles applicable to non-market services}

Achieving a global price and volume index covering all uses and resources of goods and services encounters difficulties when it comes to measuring non-market service output. The latter differ from market services in that they are not sold at market price and their value in current prices is conventionally considered equal to the sum of the costs incurred, making it almost impossible to dispose of realistic estimates of variations price or volume of production.

By their very nature, the volume and price indices used to estimate value are different from the corresponding indices used for the flow of goods and services.

\section{- Some difficulties that may arise in applying the general principles}

The application of price and volume principles to different system streams requires the adoption of solutions for the problems that they can defend.

The need to know which factors, of the ones described above, explain price differences, arises each time the chronological series of value added are studied, and when price variations have to be differentiated from volume changes. This implies that, at a detailed analysis level, the quantitative data series are only one of the approximate measures of volume variation because they do not satisfactorily reflect the variations that may occur in the composition of the different quality types. A constant number of physical units recording a given stream will in fact lead to underestimation of volume variation if the composition changes in favor of units that are of superior quality. Changes made to an average quality must be recorded as an increase in the volume index. Generally, the best way to estimate volume changes in the flows of goods and services is to deflate data that represents value using price indices. Any change in the average quality being correctly reflected in the value series, the division by a representative price index, adjusted to take account of the qualitative variations, allows us to obtain a correct volume index.

Deflation using price indices is not the only solution in practice, so other methods need to be applied. Value series can be obtained by multiplying prices and quantities, and data in constant prices can thus be obtained using the base year price. Quantities must be reported for homogeneous products. If none of the methods described is applicable, data in constant production prices should be established from the estimation of constant inputs.

\footnotetext{
${ }^{2}$ In some sectors of activity, such as in the transport sector, manufacturers can grant tariffs to groups of people whose earnings are usually lower than the average, such as pensioners or students. If they are free to travel at a time when they want, then these tariff advantages must be considered as a price differentiation. However, if they benefit from reduced fares provided they travel only during certain periods, they usually outside hours or peak periods or lower comfort classes, then estimates that they are offered a lower quality of transport.
} 
- Methods of measuring real income in the economy

For revenue streams, decomposition into a price component and a volume component is not possible. Therefore, price and volume measurement cannot be defined in the same way as flows and stocks. Income streams cannot be measured in real terms unless choosing the baskets of goods and services for which revenue is used, the price index of a particular basket being the deflator of current revenue.

Such a choice is arbitrary, however, in the sense that income is only occasionally affected by purchases during the period in question. Part can be saved for subsequent purchases or purchases during the reference period can also be made from previous savings.

The Gross Domestic Product in constant prices measures the output of the national economy (excluding intermediate consumption) in terms of volume. The total real income of residents is subject to the influence of the volume of production and the rate at which exports can be equivalent to imports.

Real Gross National Income is obtained by adding up the trade surplus and the gross domestic product volume figures. The trade surplus (deficit) is defined by the relationship:

$$
T=\frac{E X P-I M P}{I P}-\left[\frac{E X P}{I P x}-\frac{I M P}{I P m}\right] \text {, }
$$

Where:

$$
\begin{aligned}
& T \text { = trade surplus (deficit); } \\
& \text { EXP = export; } \\
& \text { IMP = import; } \\
& \text { IP = price index; } \\
& \text { IPx = import price index; } \\
& \text { IPm = export price index. }
\end{aligned}
$$

In order to reflect the various aggregates of national income in real terms, it is advisable to deflate revenues and transfers received from the rest of the world or to be paid to the rest of the world with an index of gross domestic final expenditure. Actual real national income may also be expressed in a net form by deducting from its gross value of fixed capital consumption in constant prices.

\section{- Choice of index formulas and baseline year}

Obtaining an integrated price and volume index system involves choosing the types of indices to be used.

The best way to measure volume variations of one year over another is to choose a Fisher volume index, which is defined as a geometric mean of the Laspeyres and Paasche indices.

The best way to measure one year's price variations over another is to use a Fisher price index. Price variations over longer periods can be obtained by linking price variations of one year to another. Mobilebased indices calculated on the basis of Laspeyres volume indices and used to measure variations in volume and Paasche price indices to measure one year's price variations over one another may be an acceptable substitute for the Fisher indexes. An aggregate is defined as the sum of its components. Additivity property requires that this identity be respected when the values of an aggregate and its components over a given reference period are extrapolated over time through a series of volume indices. For the main aggregates, it is recommended to compute the chain indexes of data in disaggregated constant prices, which means to directly assess the current quantities in the base year prices.

The estimation of data in constant prices should be carried out at the most detailed level if the data are to be coherent within an integrated price and volume measurement system. Tables of resources and uses constitute the central, conceptual and statistical framework of all the constant price assessments.

For constant price series it is necessary to change the base year. Since 1995, the SEC has adopted the principle of changing the base year every five years. When the base is changed, it is especially recommended to link old and new data to a base, rather than making a retroactive rebate.

No adjusted "fixed" data are published without any adjustment. This method ensures transparency and allows users to deepen the importance of the problem. 
- Elements regarding the international comparability of price and volume indices

In order to achieve price and volume comparisons at international level, the difficulty of having different national currencies needs to be overcome. Given that exchange rates are insufficiently stable for this purpose and the fact that they do not correctly reflect the differences in purchasing power, a method similar to that used for time comparisons is used. Price and volume indices need to be set for pairs of countries, applying the same type of index formulas as when measuring variations from one period to another. One of the two countries ( $A$ or $B$ ) can be used to determine the weighting coefficients. Thus, from country A's point of view, it will be possible to establish a Laspeyres-type index with weighting coefficients corresponding to country A, or a Paasche-type index using weighting coefficients obtained in country B.

If national economies in two countries are different, the difference between the two indices becomes important, but in this case the results will depend in a stronger way on the country that has been chosen as the basis. In order to resort to such binary comparisons, the SEC requires the establishment of an average between the two countries, in the form of a Fisher index.

Direct quantitative comparisons between economic situations with few common points are, in essence, difficult to achieve, and the method of deflating current values using price indices will, in this case, be the best solution. This principle applies in space comparisons and not in time comparisons. The correct specification and identification of the products will allow the calculation of the price coefficients based on the price surveys organized in each country. Since prices are recorded in national currencies, the interpretation of these price determinants requires consideration of the concept of purchasing power parity (PPP).

For nonpolar services, international comparisons are experiencing the same issues as time comparisons, which mean that the sum of entries is used to measure outputs. The method currently used in international comparisons consists in calculating PPPs based on the characteristic price coefficients of the main components of these inputs. This method, which requires comparisons of input volumes, does not take into account the productivity differences that characterize the production of non-pay services in the countries under comparison.

The SEC recognizes the need for international price and volume comparisons. The main objective is to make volume comparisons of GDP and its uses. The transitivity criterion has to be respected, which means that the direct index established for country $C$ starting from country $A$ must be equal to the indirect index obtained by multiplying the direct index for country $B$ and established starting from country $A$ with the direct index with regard to country $\mathrm{C}$ and established starting from country $\mathrm{B} .^{3}$

\section{Conclusions}

The author's study shows that buying power parity is the key to ensuring international comparability. This is because this indicator ensures and clearly presents the situation in one country or another taking into account not only the size of gross domestic product or gross domestic product/per capita or any other macroeconomic indicator of output per inhabitant but of the effective power of the value-added incomes of the population in a country, taking into account the price system in that country. In the European Union, this comparison is imperative on the basis of purchasing power and it is made easier for the group of states that have already joined the monetary union, but this should be extended to the whole European Union structure including countries that are not yet members of the European Union. In this context, the calculation of the purchasing power parity index is also relevant in providing extra-community comparisons that need to be considered both when we want to perform a complex analysis and an ordering of the elements of the structural elements that we are discussing. Another conclusion is that the purchasing power parity in the conditions of the enlargement of the European Union is flexible but that is why the theoretical methodological aspects that the authors presented in this article are to be taken into account when calculating this indicator and on the basis of which it is possible to ensure real international

\footnotetext{
${ }^{3}$ The method adopted by the SEC for calculating a multilateral volume and PPC series starts from binary comparisons between all pairs of countries considered. Although the Fisher indices used for this purpose are not transitive, it is possible to derive a series of transient indices very close to the initial Fisher indices, using the traditional least squares technique. In order to minimize the difference between the initial Fischer indices and the transitions obtained, it is recommended to apply the formula called EKS.
} 
comparability in the studies that can be undertaken. An important conclusion is that the international comparability method should be considered, the processes that are used to bring macroeconomic indicators to a real level, i.e. to express in comparison with the base year considered and chosen with great care to be of further relevance so that this level is taken into account as well as the effect of inflation that occurs annually at different rates but due to the concrete conditions that are in one country or another. We can finally conclude that the purchasing power parity in EU enlargement conditions is a relevant indicator of the utmost importance to be taken into consideration when we engage in establishing comparability of international indicators.

\section{References}

1. Angelini, P., Neri, S. and Panetta, F. (2014). The Interaction between Capital Requirements and Monetary Policy. Journal of Money, Credit and Banking, 46, 1073-1112.

2. Anghel, M.G., Lixandru, G., Popovici, M., Solomon, A.G. and Stanciu, E. (2017). Theoretical Elements on the Use of Price Indices for Inflation Measurement. International Journal of Academic Research in Accounting, Finance and Management Sciences, 7 (3), 38-47.

3. Anghelache, C., Păunică, M., Bodo, G. and Mirea, M. (2017). Aspects of optimal monetary and fiscal policies. Romanian Statistical Review, Supplement, 5, 122-138.

4. Anghelache, C., Mitruţ, C. and Voineagu, V. (2013). Statistică macroeconomică. Sistemul Conturilor Naţionale, Editura Economică, Bucureşti.

5. Azzimonti, M., Battaglini, M. and Coate, S. (2016). The Costs and Benefits of Balanced Budget Rules: Lessons from a Political Economy Model of Fiscal Policy. Journal of Public Economics, 136, 45-61.

6. Barro, R. and Redlick, C. (2011). Macroeconomic Effects from Government Purchases and Taxes, The Quarterly Journal of Economics, 126 (1), 51-102.

7. Bassetto, M. and Messer, T. (2013). Fiscal consequences of paying interest on reserves. Fiscal Studies, 34, 413-436.

8. Censolo, R. and Colombo, C. (2008). Public consumption composition in a growing economy. Journal of Macroeconomics, 30 (4), 1479-1495.

9. Christiano, L.J., Eichenbaum, M. and Rebelo, S. (2011). When is the Government Spending Multiplier Large?, Journal of Political Economy, 119 (1), 78-121.

10.Farhi, E. and Werning, I. (2016). A Theory of Macroprudential Policies in the Presence of Nominal Rigidities. Econometrica, 84, 1645-1704.

11.Kaplan, G. and Violante, G. (2014). A model of the consumption response to fiscal stimulus payments, Econometrica, 82 (4), 1199-1239.

12.Gali, J., Lopez-Salido, J.D. and Valles, J. (2007). Understanding the Effects of Government Spending on Consumption. Journal of the European Economic Association, 5 (1), 227-270.

13.Greenwood, R. and Nagel, S. (2009). Inexperienced Investors and Bubbles. Journal of Financial Economics, 93, 239-258.

14.Mian, A., Rao, K. and Sufi, A. (2013). Household Balance Sheets, Consumption, and the Economic Slump. Quarterly Journal of Economics, 128 (4), 1687-1726.

15.Romer, C. and Romer, D. (2010). The Macroeconomic Effects of Tax Changes: Estimates Based on a New Measure of Fiscal Shocks. American Economic Review, 100 (3), 763-801.

16.Solomon, M.R., Bamossy, G., Askegaard, S. and Hogg, M.K. (2006). Consumer behavior: a European perspective, Third Edition, Prentice Hall.

17.Tracy, J. and Wright, J. (2016). Payment Changes and Default Risk: The Impact of Refinancing on Expected Credit Losses. Journal of Urban Economics, 93, 60-70. 